\title{
Inflammatory bowel disease patients prioritize
} mucosal healing, symptom control, and pain when choosing therapies: results of a prospective crosssectional willingness-to-pay study

This article was published in the following Dove Press journal:

Patient Preference and Adherence

James C Gregor,' Martin

Williamson, ${ }^{2}$ Dorota

Dajnowiec, ${ }^{2}$ Bernie Sattin, ${ }^{2}$

Erik Sabot, ${ }^{3}$ Baljinder Salh ${ }^{4}$

'Division of Gastroenterology, Department of Medicine, Western University, London, ON, Canada; 2Janssen Inc., Toronto, ON, Canada; ${ }^{3}$ OptumInsight, Boston, MA, USA;

${ }^{4}$ Division of Gastroenterology,

Department of Medicine, University of British Columbia, Vancouver,

BC, Canada

Video abstract

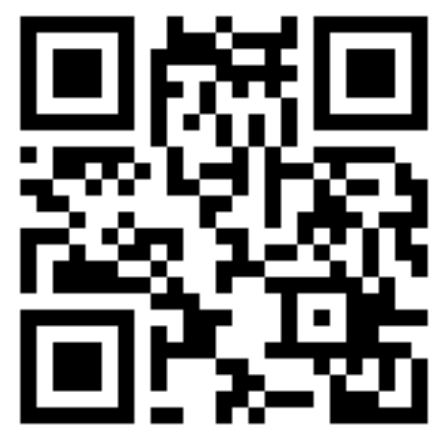

Point your SmartPhone at the code above. If you have a QR code reader the video abstract will appear. Or use:

http://youtu.be/0IU ISmWT4A

Correspondence: Baljinder Salh Division of Gastroenterology, University of British Columbia,

2775 Laurel Street, Vancouver,

BC, Canada V5Z IM9

$\mathrm{Tel}+\mathrm{I} 6048755224$

Fax +l 8886336293

Email bill.salh@ubc.ca
Background: Given the large armamentarium of therapies for inflammatory bowel disease (IBD), physicians cannot fully describe all treatments to patients and, therefore, make assumptions regarding treatment attributes communicated to patients. This study aimed to assess outof-pocket willingness-to-pay that IBD patients allocate to treatment attributes.

Methods: Adult patients receiving therapy for IBD were invited to access a cross-sectional web-based discrete-choice experiment (May 22-August 31, 2015) that presented paired medication scenarios with varying efficacy, safety, and administration parameters. Preference weights and willingness-to-pay for each attribute level were assessed by a hierarchical Bayes method including a multinomial logit model.

Results: A total of 586 IBD patients were included, 404 (68.9\%) with Crohn's disease and $182(31.1 \%)$ with ulcerative colitis. Genders were evenly distributed; the majority of patients (70.1\%) were 50 years or younger and had postsecondary education $(75.4 \%)$, while the median health status was 7 (Likert scale: 1 [poor] - 10 [perfect]). Regarding relative preference-weight estimates, for the average respondent, reducing pain during administration, mucosal healing, and symptom relief were the highest-ranking attributes. Conversely, infusion reactions and risk of hospitalization or surgery were the lowest-ranking attributes. In multivariate analysis, patient sociodemographics did not affect the rank order of attributes although small differences were observed between asymptomatic and symptomatic patients in the previous year.

Conclusion: This study has important implications related to understanding patient preferences and designing patient-centered strategies. IBD patients prioritize treatments with low administration pain. Additionally, these results concur with treatment guidelines emphasizing patients' preference for mucosal healing and symptom control.

Keywords: inflammatory bowel disease, patient preference, willingness-to-pay, discrete choice

\section{Introduction}

Inflammatory bowel disease (IBD), mainly encompassing Crohn's disease (CD) and ulcerative colitis (UC), is a chronic immune-mediated condition primarily affecting the gastrointestinal tract. Common IBD symptoms may include diarrhea, abdominal pain, gastrointestinal bleeding, weight loss, and psychological distress. ${ }^{1-3} \mathrm{CD}$ and UC patients experience periods of remission and relapse, the latter generally triggered by environmental factors and characterized by intensification of symptoms. ${ }^{4}$

IBD therapy aims to eliminate symptoms, prevent relapses, and restore quality of life. ${ }^{5,6}$ Current IBD treatment options include 5-aminosalicylates, corticosteroids, antibiotics, 
immunosuppressives, such as azathioprine, mercaptopurine, and methotrexate, and biologic drugs, such as infliximab, adalimumab, golimumab, and more recently, vedolizumab, and ustekinumab. ${ }^{2,5,7,8}$ Drug profiles vary considerably in regard to mode and frequency of administration, efficacy, as well as risk of short- and long-term safety, among others. ${ }^{2}$

While various appropriate treatment options are available, ${ }^{9}$ providing patients with a detailed complete description of all treatment profiles can be challenging in routine clinical practice due to time constraints. This often leads to a communication gap between health care professionals (HCPs) and patients: ${ }^{10,11}$ Patients and clinicians may have difficulty prioritizing treatment attributes and might make assumptions with respect to the specific topics to discuss in counseling. However, patient engagement during counseling and treatment selection is important, and has even been shown to improve outcomes. ${ }^{12}$ As the various IBD therapies present with differing features, ${ }^{2,13}$ patient input allows the customization of treatment according to their preferences which would often differ from those of their physicians. ${ }^{14}$ Moreover, previous studies ${ }^{15,16}$ have shown that the involvement of patients in therapy selection may improve adherence to treatment, a common issue in the management of chronic diseases such as IBD, which may subsequently lead to improved treatment effectiveness.

Increased physician awareness of patients' therapy priorities could help remove this gap while still maintaining the time-efficient qualities of the standard therapy selection approach. However, to date, published data to guide HCPs are scarce. One common approach to understanding patient preferences is to perform conjoint analysis (eg, willingness-to-pay [WTP]). WTP studies can provide generalized information about patient interest in treatment attributes for the clinician. Thus, the treatment attribute and benefit-risk profiles (which vary between available IBD medications) can be constructed to refine the communication of differences between IBD therapies and biologics to patients. ${ }^{2}$

The aims of the current study were to determine IBD patients' WTP for various treatment features, as well as explore patients' demographic and disease characteristics that may be associated with their WTP.

\section{Materials and methods Study design}

This was a single-arm, cross-sectional discrete-choice survey of IBD patients. Eligible patients providing written informed consent were directed to a web-based platform which included a defined number of theoretical comparisons of treatment options. A sample questionnaire and the study protocol can be found in the online supplement.

Attribute levels were obtained from ranges observed in randomized controlled trials, then vetted by the authors. The survey was pilot-tested in telephone interviews with three patients to ensure the questionnaire's validity.

The model presented paired medication scenarios to respondents with varying efficacy, safety, and administration parameters (Table 1). Discrete-choice/conjoint analysis was conducted to assess the value of certain product attributes (in \$CAD out of pocket per month) in relation to others, allowing the identification of characteristics with the highest value as perceived by patients. Preference weights and WTP for each attribute level were assessed by a hierarchical Bayes method including a multinomial logit model.

In the WTP analysis, 12 attributes were included and were classified into three meaningful categories: 1) "administration characteristics" such as pain on administration, dosing schedule, and mode of administration; 2) "efficacy outcomes" comprising symptom relief, mucosal healing, speed of onset, and need for steroids; and 3) "safety risks" including injection reactions, time on market/number of patients exposed, chance of surgery or hospitalization in the following year, and infusion reactions.

Table I Treatment features and attribute levels for WTP survey

\begin{tabular}{|c|c|}
\hline Attributes & Levels \\
\hline \multirow[t]{4}{*}{ Mode of administration } & Take a pill by mouth \\
\hline & Inject the medicine by yourself \\
\hline & Infusion that requires $30-60$ minutes \\
\hline & Infusion that requires $2-3$ hours \\
\hline \multirow[t]{4}{*}{ Dosing schedule } & Every day \\
\hline & Every 2 weeks \\
\hline & Every 4 weeks \\
\hline & Every 8 weeks \\
\hline Symptom relief & $20 / 40 / 60 / 80$ out of 100 patients in I year \\
\hline Mucosal healing & $20 / 40 / 60 / 80$ out of 100 patients in I year \\
\hline Need for steroids & $20 / 40 / 60 / 80$ out of 100 patients in I year \\
\hline $\begin{array}{l}\text { Chance of hospitalization } \\
\text { in next year }\end{array}$ & 10 or 20 out of 100 patients \\
\hline $\begin{array}{l}\text { Chance of surgery in } \\
\text { next year }\end{array}$ & I-4 out of 100 patients \\
\hline Pain during administration & $0 / 2 / 4 / 6 / 8$ on a scale of $0-10$ \\
\hline Time on market/number & New/500 patients \\
\hline \multirow[t]{2}{*}{ of patients exposed } & 3 years $/ 500,000$ patients \\
\hline & 10 years/millions of patients \\
\hline \multirow[t]{2}{*}{ Speed of onset } & Same day/I week/2 weeks/I month/ \\
\hline & 2 months $/ 4$ months \\
\hline Injection reaction & 0/4/40 per person every year \\
\hline Infusion reaction & $0 / 3$ per person every year \\
\hline
\end{tabular}

Abbreviation: WTP, willingness-to-pay. 


\section{Study population}

Canadian adults aged $18-75$ years with a self-reported diagnosis of IBD, including CD or UC, who received therapy within a nationwide patient support program between May and August 2015 were invited to participate in the study by means of printed materials. Patients were excluded if they were unwilling to complete the survey.

Consistency of responses was verified with root likelihood approach; ${ }^{17}$ scores below 500 were defined as inconsistent and were excluded from the analysis. Subjects that did not report having IBD were defined as non-IBD and were excluded from the analysis.

\section{Statistical methods}

The validity of the partial-profile design was tested with simulated data for 400 respondents. The simulated data produced estimates of the attributes with sufficient precision (ie, standard errors of the attribute estimates no larger than 0.05 ) to proceed with the selected experimental design. More precisely, the Advanced Test of Sawtooth CBC software (Sawtooth Software Inc, Provo, UT, USA) was used to determine the strength of the design, D-Efficiency. The test randomly generated the data for the 400 respondents and provided estimates using multinomial logit.

Frequency distributions were produced for sociodemographic variables and types of treatments used. Estimates of WTP to alternate between two levels of a given attribute were derived initially by determining the difference in estimated utility between the two levels (difference in preference weights). WTP to alternate between the two previously identified levels was estimated by determining the change in out-of-pocket costs required to obtain an equivalent utility change. In addition, as we hypothesized that patients reporting active disease may have differing preferences to those reporting controlled disease, we therefore explored this factor with the aid of univariate and multivariate analysis of variance to analyze the WTP based on patient-reported disease status in the last 12 months (remission vs symptomatic). Utility estimates from the hierarchical Bayesian analysis were used to examine between-group differences in regard to the dollar-scaled WTP values. Preferences were determined with the aid of the hierarchical Bayesian model where the means of the individual estimates of attribute level utilities were compared between groups. Sawtooth Software Inc., CBC Hierarchical Bayes Module (version 5.5.3), Microsoft Excel (version 14.0), and Stata/ SE (version 12.1) were utilized to conduct the statistical analyses.

\section{Ethical considerations}

The study was approved by Institutional Review Board Services, a Canadian central ethics board, on April 30, 2015. The study methodology complied with Good Clinical Practices, Health Canada regulations, FDA 21 CFR parts 50 and 56, DHHS 45 CFR part 46, and the Tri-Council Policy Statement for Ethical Conduct of Research Involving Humans.

\section{Results}

One thousand one-hundred and twenty-seven $(1,127)$ patients were enrolled in the study. Seven hundred fortyfour (744) patients responded to the survey, of whom 93 and 65 patients were excluded from the analysis due to inconsistent survey responses and likely non-IBD diagnosis, respectively. Therefore, 586 patients diagnosed with IBD were included, of whom 404 (68.9\%) and 182 (31.1\%) had CD and UC, respectively. Table 2 shows the

Table 2 Baseline characteristics of WTP survey respondents reporting a diagnosis of IBD $(\mathrm{N}=586)$

\begin{tabular}{|c|c|}
\hline \multirow[t]{2}{*}{ Sociodemographics characteristic } & \multirow{2}{*}{$\begin{array}{l}n(\%) \\
\mathrm{N}=586\end{array}$} \\
\hline & \\
\hline \multicolumn{2}{|l|}{ IBD type, n (\%) } \\
\hline$C D$ & $404(68.9 \%)$ \\
\hline UC & $182(31.1 \%)$ \\
\hline \multicolumn{2}{|l|}{ Age category (years), n (\%) } \\
\hline$<21$ & $23(3.9 \%)$ \\
\hline $21-30$ & $126(2 \mid .5 \%)$ \\
\hline $31-40$ & 145 (24.7\%) \\
\hline $4 I-50$ & II 7 (20.0\%) \\
\hline $51-60$ & $98(16.7 \%)$ \\
\hline$>60$ & $50(8.5 \%)$ \\
\hline No response & $27(4.6 \%)$ \\
\hline \multicolumn{2}{|l|}{ Gender, n (\%) } \\
\hline Female & $285(48.6 \%)$ \\
\hline Male & $274(46.8 \%)$ \\
\hline No response & $27(4.6 \%)$ \\
\hline \multicolumn{2}{|l|}{ Racial background, n (\%) } \\
\hline Asian & II (I.9\%) \\
\hline Black & $3(0.5 \%)$ \\
\hline Caucasian & $509(86.9 \%)$ \\
\hline No response & $46(7.8 \%)$ \\
\hline Other & 17 (2.9\%) \\
\hline \multicolumn{2}{|l|}{ Highest level of education, $n(\%)$} \\
\hline Less than high school & $14(2.4 \%)$ \\
\hline High school & 91 (I5.5\%) \\
\hline Some college or technical school & $231(39.4 \%)$ \\
\hline University degree & $160(27.3 \%)$ \\
\hline Graduate degree & $27(4.6 \%)$ \\
\hline Professional degree ${ }^{\mathrm{a}}$ & $24(4.1 \%)$ \\
\hline No response & $39(6.7 \%)$ \\
\hline
\end{tabular}


Table 2 (Continued)

\begin{tabular}{ll}
\hline Sociodemographics characteristic & $\mathbf{n}(\%)$ \\
& $\mathbf{N}=\mathbf{5 8 6}$ \\
\hline Employment status, $\mathrm{n}(\%)$ & \\
Full-time $(>30$ hours/wk) & $344(58.7 \%)$ \\
Part-time & $50(8.5 \%)$ \\
Homemaker & $23(3.9 \%)$ \\
Student & $39(6.7 \%)$ \\
Retired & $54(9.2 \%)$ \\
Not currently employed & $40(6.8 \%)$ \\
No response & $36(9.4 \%)$ \\
Household income & \\
Under $\$ 20,000$ & $53(9.0 \%)$ \\
$\$ 20,000-\$ 39,999$ & $64(10.9 \%)$ \\
$\$ 40,000-\$ 59,999$ & $91(15.5 \%)$ \\
$\$ 60,000-\$ 79,999$ & $61(10.4 \%)$ \\
$\$ 80,000-\$ 99,999$ & $57(9.7 \%)$ \\
$\$ 100,000-\$ 124,999$ & $59(10.1 \%)$ \\
$\$ 125,000-\$ 149,999$ & $30(5.1 \%)$ \\
$\$ 150,000-\$ 199,999$ & $31(5.3 \%)$ \\
$\$ 200,000$ or more & $9(1.5 \%)$ \\
No response & $131(22.4 \%)$ \\
Overall health status, ${ }^{b} \mathrm{n}(\%)$ & \\
I & \\
2 & $1(0.2 \%)$ \\
3 & $5(0.8 \%)$ \\
4 & $21(3.6 \%)$ \\
6 & $23(3.9 \%)$ \\
7 & $43(7.4 \%)$ \\
8 & $80(13.7 \%)$ \\
No response & $126(21.5 \%)$ \\
\hline
\end{tabular}

Notes: ancluding MD, LLB, DVM, DD, DDS. 'Higher scores indicate improved health status.

Abbreviations: CD, Crohn's disease; DD, Doctor of Divinity; DDS, Doctor of Dental Surgery; DVM, Doctor of Veterinary Medicine; IBD, inflammatory bowel disease; LLB, Literally Legum Baccalaureus; MD, Medicinae Doctor; UC, ulcerative colitis; wk, week; WTP, willingness-to-pay.

sociodemographic results of the study population. Genders were equally distributed. The majority of patients were 50 years of age or younger $(70.1 \%)$, Caucasian $(86.9 \%)$, had postsecondary education (75.4\%), and were employed on a full-time basis (58.7\%). The median household income was between $\$ 60,000$ and $\$ 79,999$. On a scale between 0 and 10 points, where higher scores indicate improved health status, the majority of patients rated their own overall health status as good, with $25.9 \%$ of patients reporting a score of 8 points, followed by $7(21.5 \%), 9(13.8 \%)$, and $6(13.7 \%)$ points.

Table 3 presents previous and current IBD therapy. The majority of patients had previously received infliximab (91\% of patients), steroids (67\%), and azathioprine or
Table 3 Previous and current therapies of WTP survey respondents reporting a diagnosis of IBD

\begin{tabular}{|c|c|c|}
\hline \multirow{2}{*}{$\begin{array}{l}\text { Previous and current types of } \\
\text { therapy }\end{array}$} & \multirow{2}{*}{$\frac{\text { Ever use }}{\text { n (\%) }}$} & \multirow{2}{*}{$\frac{\text { Current use }^{\mathrm{b}}}{\mathrm{n}(\%)}$} \\
\hline & & \\
\hline \multicolumn{3}{|l|}{ Biologic treatment } \\
\hline Infliximab & $532(90.8 \%)$ & 527 (89.9\%) \\
\hline Adalimumab & $58(9.9 \%)$ & $2(0.3 \%)$ \\
\hline Golimumab & $3(0.5 \%)$ & $2(0.3 \%)$ \\
\hline Ustekinumab & $2(0.3 \%)$ & $2(0.3 \%)$ \\
\hline Etanercept & $4(0.7 \%)$ & $0(0.0 \%)$ \\
\hline \multicolumn{3}{|l|}{ Nonbiologic treatment } \\
\hline Azathioprine or mercaptopurine & $328(56.0 \%)$ & |4| (24.1\%) \\
\hline Methotrexate & $67(11.4 \%)$ & $28(4.8 \%)$ \\
\hline Steroids & $391(66.7 \%)$ & $43(7.3 \%)$ \\
\hline 5-aminosalicylic acid & $232(39.6 \%)$ & 55 (9.4\%) \\
\hline Antibiotics & $108(18.4 \%)$ & $16(2.7 \%)$ \\
\hline Investigational treatment & I54 (26.3\%) & $8(1.4 \%)$ \\
\hline
\end{tabular}

Notes: aPatients may have reported the use of multiple types of treatment. 'The column total does not sum to $100 \%$ as the treatment type categories are not mutually exclusive.

Abbreviations: IBD, inflammatory bowel disease; WTP, willingness-to-pay.

mercaptopurine (56\%), followed by 5 -aminosalicylic acid (40\%), investigational treatments (26\%), antibiotics (18\%), methotrexate $(11 \%)$, and adalimumab (10\%). Nearly all $(90 \%)$ patients were currently receiving infliximab, while $24 \%$ and $9 \%$ of patients were presently being treated with azathioprine or mercaptopurine and 5-aminosalicylic acid, respectively.

Figure 1 shows the sample's WTP (out of pocket, per month) for all assessed attributes. The most valued treatment features reported by IBD patients included: pain during administration, followed by mucosal healing and symptom relief; patients were prepared to pay more for lower pain $(\$ 1,875)$, increased mucosal healing $(\$ 1,584)$, and higher symptom relief $(\$ 1,450)$. The least valued treatment features assessed by IBD patients included infusion reactions (\$261), chance of hospitalization in the next year (\$337), chance of surgery in the next year (\$535), time on market/number of patients exposed (\$563), mode of administration (\$700), injection site reactions (\$766), and dosing schedule (\$788), from the least to the most important attribute; patients were willing to pay under $\$ 800$ monthly for the preferred option for each of these parameters.

Figure 2 presents the results of the subgroup analysis comparing the WTP of stable asymptomatic patients $(\mathrm{n}=191)$ with symptomatic recurrence in the last 12 months $(\mathrm{n}=356)$ (29 patients had missing data in regard to remission/ symptomatic recurrence). Comparable to the findings shown in Figure 1, patients in remission and in relapse accorded the highest WTP to pain during administration, mucosal healing, and symptom relief. The overall rank order of attributes was 
similar between groups; however, subtle differences were reported in regard to the cost patients were prepared to pay for certain parameters. Specifically, patients in stable remission reported slightly higher WTP for: no pain during administration (patients in remission vs patients with symptoms: $\$ 1,927$ vs $\$ 1,755)$, steroid sparing ( $\$ 1,141$ vs $\$ 863$ ), the absence of injection site reactions ( $\$ 866$ vs $\$ 641$ ), more years on the market/patients exposed (\$741 vs $\$ 470$ ), lower probability of surgery in the following year ( $\$ 741$ vs $\$ 470$ ), and the absence of infusion reactions ( $\$ 364$ vs $\$ 182$ ). Conversely, patients with symptoms were willing to pay slightly more for symptom relief $(\$ 1,329$ vs $\$ 1,502)$ as well as mode of administration (oral or infusion compared to injection [ $\$ 445$ vs $\$ 655$ for oral administration]). Similar WTP was observed between these groups in regard to improved mucosal healing ( $\$ 1,600$ vs $\$ 1,548)$, same-day onset $(\$ 1,009$ vs $\$ 1,097)$, and infrequent dosing schedule (\$778 vs $\$ 758$ ).

The observed differences in WTP for symptom relief and speed of onset are statistically significant $(p<0.05)$. Patients reporting remission were also willing to pay greater total out-of-pocket costs than those not in remission $(p<0.05)$. In a subanalysis which differentiated $\mathrm{UC}$ and $\mathrm{CD}$ patients, no remarkable differences were observed in regard to WTP (data not shown).

A

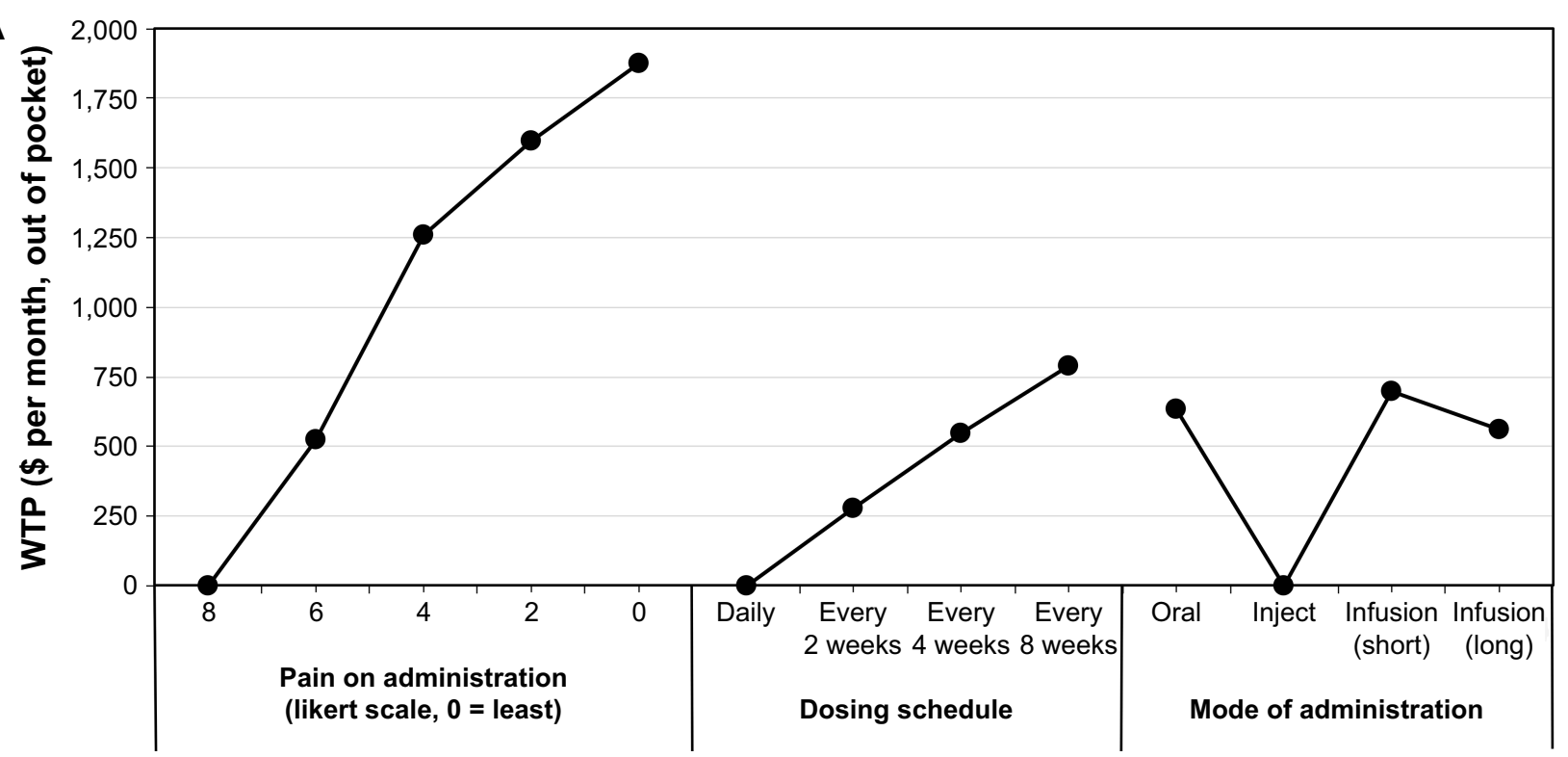

B

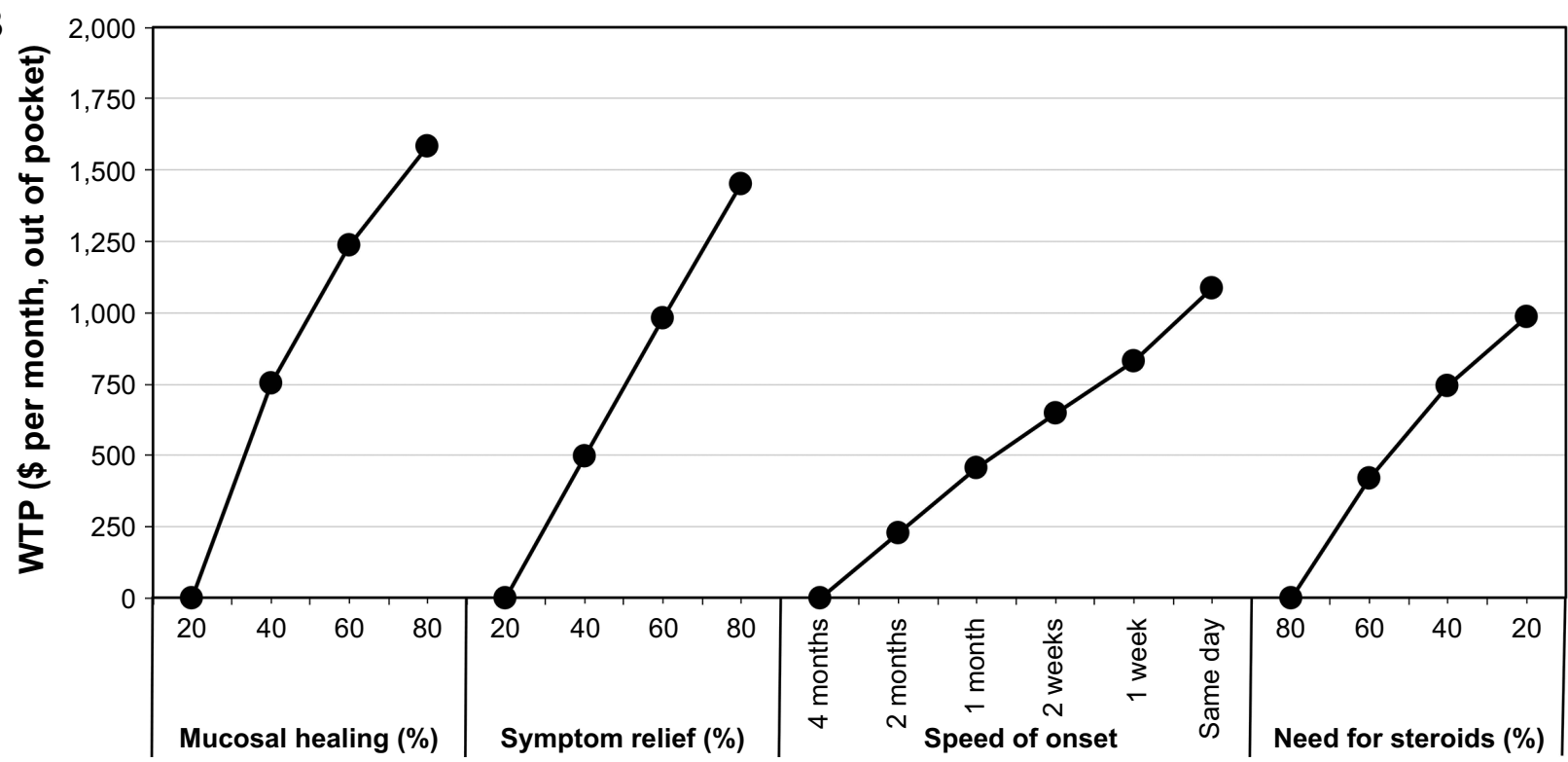

Figure I (Continued) 


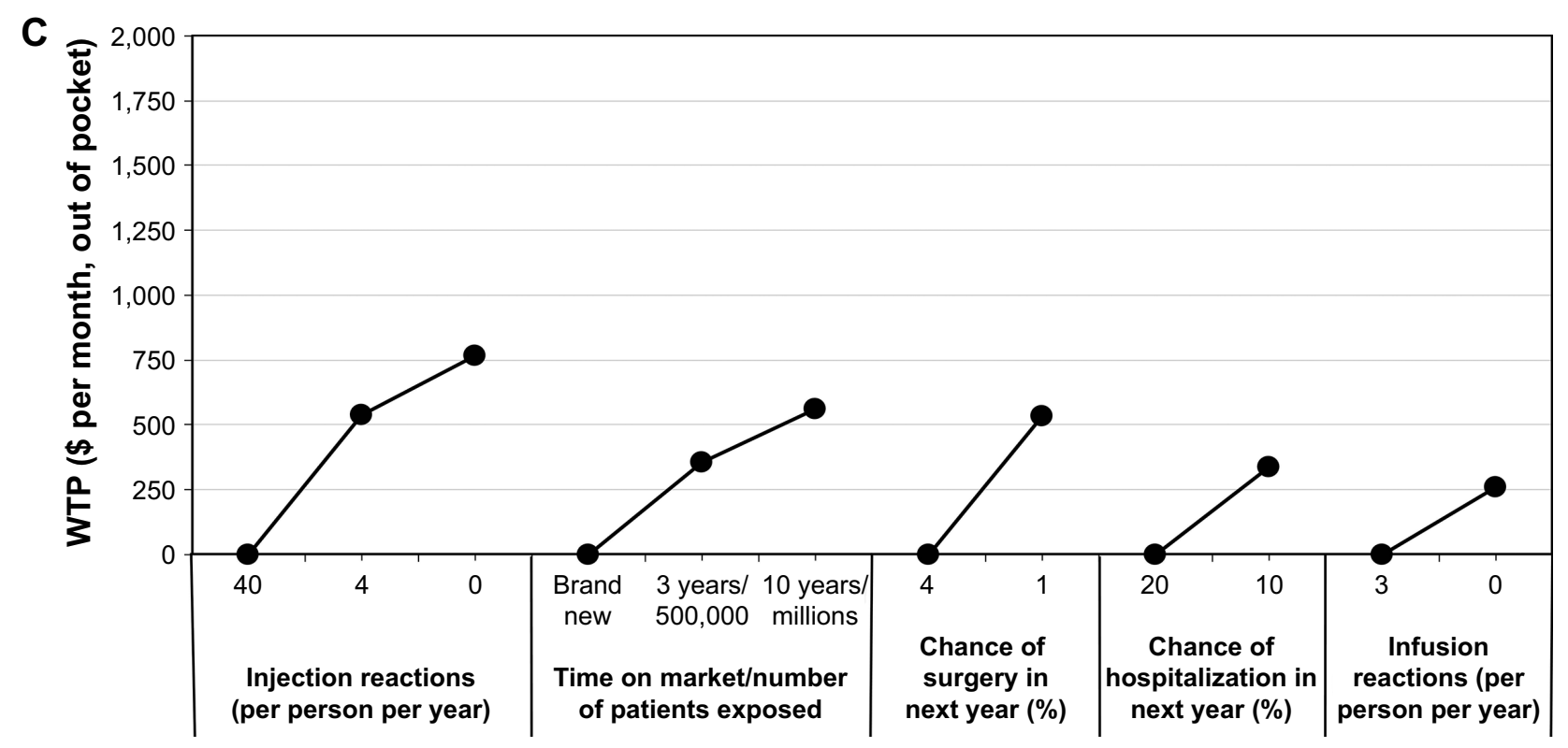

Figure I WTP (\$ per month, out of pocket) for $\mathrm{N}=586$ respondents reporting a diagnosis of IBD.

Notes: (A) Administration characteristics, (B) efficacy outcomes, and (C) safety risks. Each WTP estimate shows the value that the average respondent would place on a specific outcome or product attribute. A higher WTP indicates a more preferred outcome or product attribute. Lowest valued attribute is set to $\$ 0$ per month, out of pocket, in each category. When comparing across attributes, those with the highest absolute WTP are ranked the most important to respondents.

Abbreviations: IBD, inflammatory bowel disease; WTP, willingness-to-pay.

\section{Discussion}

This study aimed to assess the preferences of IBD patients in terms of treatment attributes and WTP. Surprisingly, patients allocated higher WTP to pain during administration, a temporary outcome, than IBD improvement including mucosal healing and symptom relief, which were previously identified as treatment priorities in published guidelines. ${ }^{2,18}$ Conversely, infusion reactions, risk of surgery or hospitalization in the next year, exposure to drug, and mode of administration were lower-ranking features to patients, suggesting that patients prioritize symptom improvement over the potential risk of short- and long-term consequences.

Overall, for the preferred option of treatment attributes, patients reported WTP values between $\$ 261$ and $\$ 1,875$

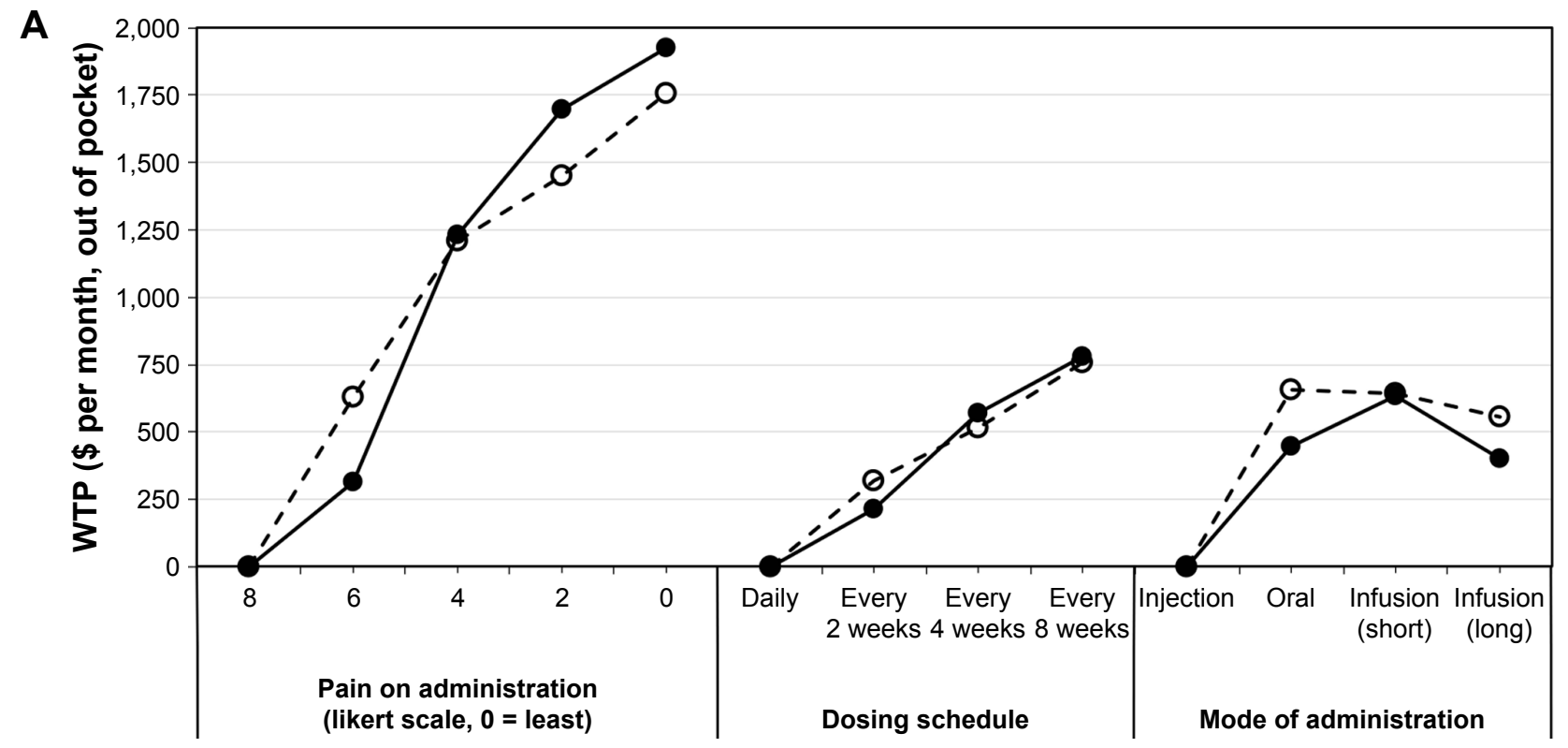

Figure 2 (Continued) 
B

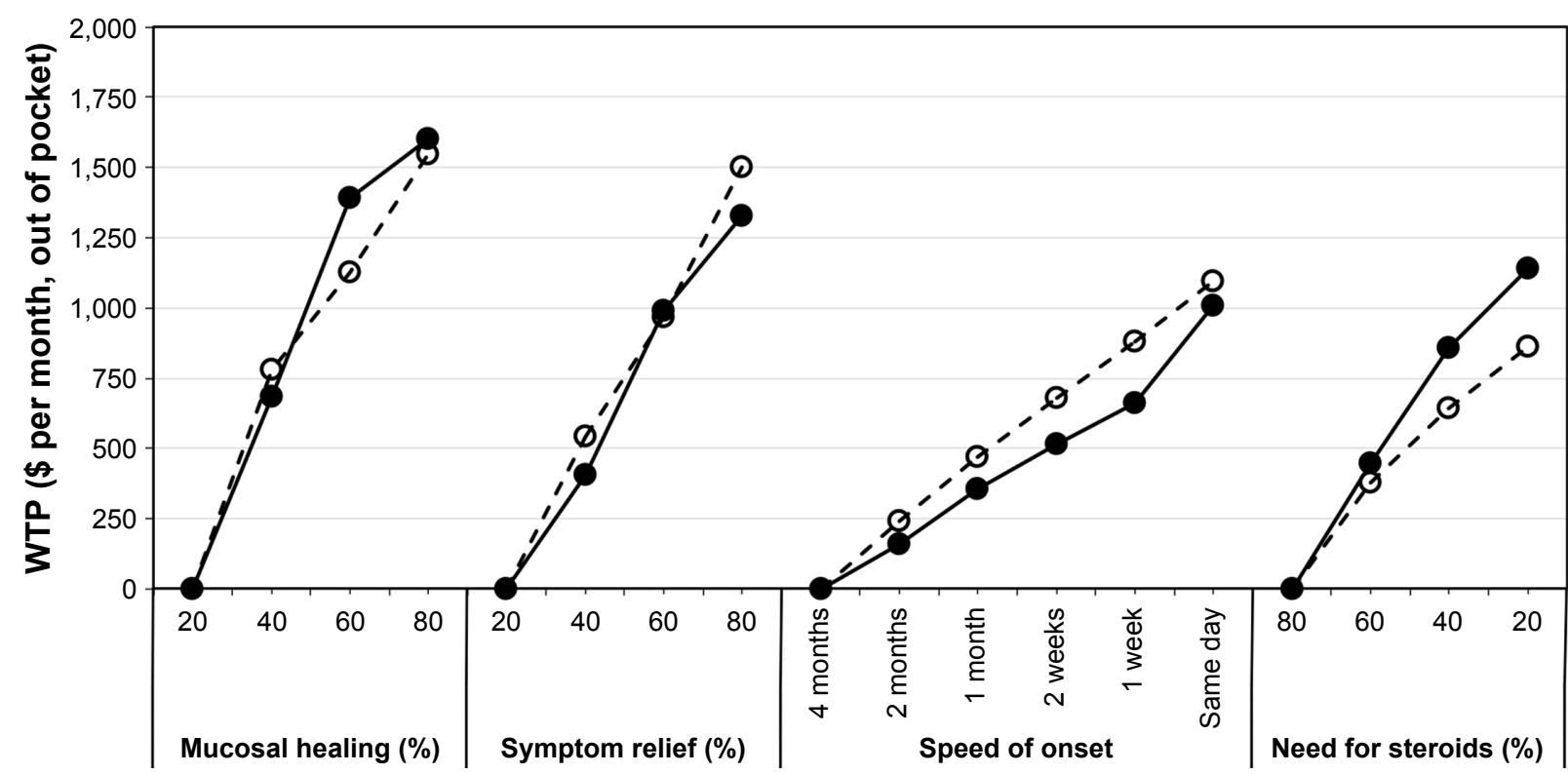

C

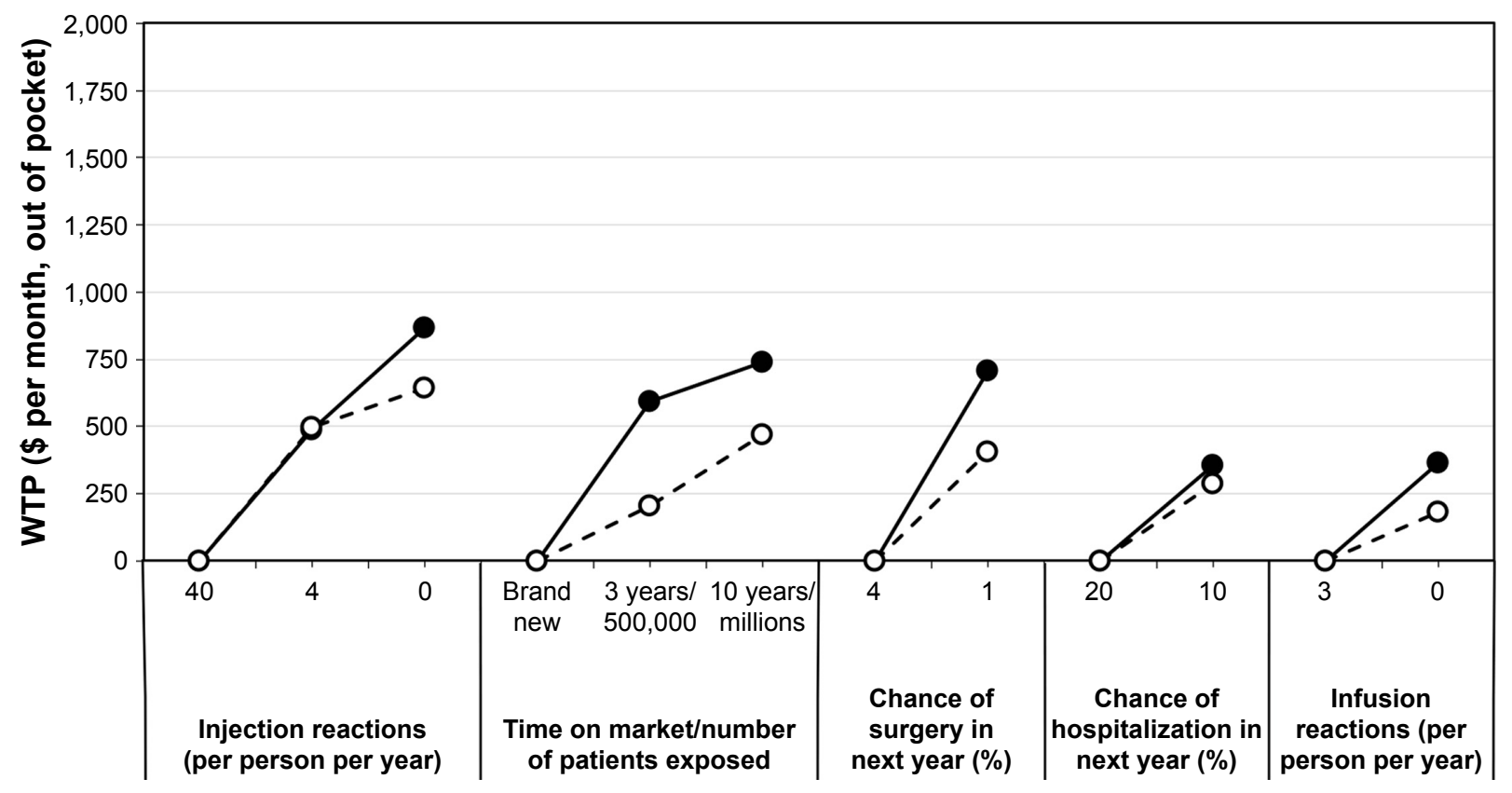

Stable asymptomatic patients

Patients with presence of symptoms

Figure 2 WTP (\$ per month, out of pocket) for stable asymptomatic patients (no symptoms during previous 12 months, $\mathrm{n}=224$ ) or patients with presence of symptoms ( $\geq$ I episode of symptoms or disease worsening in previous 12 months, $n=362$ ).

Notes: (A) Administration characteristics, (B) efficacy outcomes, and (C) safety risks. Each WTP estimate shows the value that the average respondent would place on a specific outcome or product attribute. A higher WTP indicates a more preferred outcome or product attribute. Lowest valued attribute is set to $\$ 0$ per month, out of pocket, in each category. When comparing across attributes, those with the highest absolute WTP are ranked the most important to respondents.

Abbreviation: WTP, willingness-to-pay.

(per month, out of pocket) for the absence of infusion reactions and pain during administration, respectively. As this study reported monthly WTP, costs could cumulatively escalate over time, particularly due to the chronic nature of IBD associated with long-term therapy. The high monetary values reported by patients, even among the attributes of lesser importance, demonstrate the important burden of IBD patients and the need to improve treatment management according to patients' preferences.

With respect to the subgroup analysis of patients in stable remission and patients with symptoms, the overall rank order of attributes was overall consistent; however, 
the value attributed to certain parameters varied between groups. Specifically, patients with symptomatic recurrence were more willing to receive medications that are new or associated with an increased risk of surgery, need for steroids, or injection site reactions if they increase the possibility of positive treatment outcomes.

The results of the current analysis generally concur with previous published findings. Specifically, previous studies have shown that IBD patients typically prioritize symptom improvement and are willing to accept aggressive treatments associated with higher risks of adverse events if greater benefits are anticipated. ${ }^{19}$ Our results are in agreement with those of the Canadian study led by Gray et $\mathrm{al}^{20}$ conducted on UC patients; overall, patients prioritized symptom relief and speed of onset over frequency and route of administration. ${ }^{20}$ In the study by Lichtenstein et $\mathrm{al}^{21}$ including CD patients, lasting remission and rapidity of response were assigned higher importance over the need for steroids, mode of administration, and number of patients previously exposed. However, the highest-ranking feature in the Lichtenstein study was frequency of administration, though this was rated as an attribute of lesser importance in the current study. Moreover, similar to the present study results, Sylwestrzak et $\mathrm{al}^{22}$ and Allen et $\mathrm{al}^{23}$ reported patients preferred infusion administration over subcutaneous treatment. There is discordance in the available literature, and more research is needed to control for the discrepancy.

The current study has certain limitations. For instance, survey bias may have occurred due to the inclusion of patients with a likely advanced disease. Indeed, this speculation is substantiated by the high prevalence of patients receiving biologic therapies. ${ }^{2,18}$ The generalizability of results may have been reduced due to the good health status of the majority of patients and the utilization of a nationwide patient support program for the study's patient population. However, when examining patients that reported poorer health status, the overall rank order of the attributes did not change, although some individual attributes did have higher WTP. This suggests the results may be more widely generalizable than anticipated from the selected sample. Moreover, as the majority of patients (94\%) were receiving infliximab, they may have been biased to report results favoring efficacy and speed of onset. As a result, we infer that the presented results are a surrogate to biologic-naïve patients. Furthermore, the dimension of time was generally not captured for various components and was therefore not adjusted for in the analysis. For instance, a lengthy administration may have influenced patients to report higher WTP for lower pain on administration and an infrequent dosing schedule.
Our analysis was restricted to patients that were receiving biologics; however, the relative importance of attributes in our study was consistent with those observed in other studies of nonbiologic-treated patients. ${ }^{24}$ Finally, although we believe that the analysis reasonably converted utilities to dollar values, the interpretation of monetary value for patient's WTP can be overestimates; ${ }^{25}$ therefore, the present results may be interpreted in the sense that a patient is willing to pay a certain amount for an attribute level compared to the base attribute level if all remaining attributes are equivalent.

This study has important implications related to understanding patient preferences and designing patient-centric treatment strategies. Since $98 \%$ of IBD patients believe that patients' active involvement in the therapy selection process is important, as shown by a self-empowerment study, ${ }^{26}$ treatment customization according to patients' preferences will likely lead to improved $\mathrm{HCP}$-patient communication and treatment compliance. Also, the results of the present study may assist guideline development in order to incorporate patient preferences. Currently, the achievement and maintenance of remission while incorporating patient's perspective is a recommended treatment goal set forth by the European Crohn's and Colitis Organization. However, the guidelines provide no elaboration to guide HCPs in regard to the attributes that patients prioritize. ${ }^{27-29}$ Therefore, the specific parameters for which patients have reported higher WTP may be of interest for potential inclusion in treatment guidelines, particularly pain during administration as quality of life remains an important objective of IBD therapy.

\section{Conclusion}

Overall, IBD patients appear most willing to pay for therapies associated with low administration pain, high mucosal healing, and improved symptom control. Subtle differences in WTP were observed between patients in remission as compared to symptomatic patients suggesting that the latter group seem prepared to accept therapy associated with infusion reactions and risk of surgery or hospitalization in the next year. These findings provide insight into understanding patient preferences that may enhance informed patientcentered decisions and strategies in IBD management.

\section{Acknowledgments}

The authors wish to thank Dr Angela Karellis and Ms Clare Pollock for manuscript writing support.

\section{Disclosure}

Martin Williamson, Dorota Dajnowiec, and Bernie Sattin are employees and stock shareholders of Janssen Inc. 
James C Gregor has acted as an adviser/speaker for AbbVie, Allergan, Janssen, and Takeda and has received research support from Takeda. Erik Sabot is an employee of Optum; Optum received a consulting fee from Janssen Canada for this study. Baljinder Salh has acted as a speaker for Janssen, Takeda, Abbvie, Pendopharm, and Allergan and has acted as an adviser for Janssen and Takeda. Janssen Inc. funded this study. The authors report no other conflicts of interest in this work.

\section{References}

1. Rubin DC, Shaker A, Levin MS. Chronic intestinal inflammation: inflammatory bowel disease and colitis-associated colon cancer. Front Immunol. 2012;3:107.

2. Mowat C, Cole A, Windsor A, et al. Guidelines for the management of inflammatory bowel disease in adults. Gut. 2011;60:571-607.

3. Farrell D, McCarthy G, Savage E. Self-reported symptom burden in individuals with inflammatory bowel disease. J Crohns Colitis. 2016;10: 315-322.

4. Liverani E, Scaioli E, Digby RJ, et al. How to predict clinical relapse in inflammatory bowel disease patients. World J Gastroenterol. 2016;22 1017-1033.

5. Foundation CDH. Best practices in IBD care. Taking steps to introduce an integrated multidisciplinary patient-centric care model; 2013. Available from: http://www.cdhf.ca/bank/document_en/75best-practices-inibd-care.pdf. Accessed July 6, 2016.

6. Sohrabpour AA, Malekzadeh R, Keshavarzian A. Current therapeutic approaches in inflammatory bowel disease. Curr Pharm Des. 2010;16: 3668-3683.

7. Burger D, Travis S. Conventional medical management of inflammatory bowel disease. Gastroenterology. 2011;140:1827.e2-1837.e2.

8. Amiot A, Peyrin-Biroulet L. Current, new and future biological agents on the horizon for the treatment of inflammatory bowel diseases. Therap Adv Gastroenterol. 2015;8:66-82.

9. Siegel CA. Making therapeutic decisions in inflammatory bowel disease: the role of patients. Curr Opin Gastroenterol. 2009;25:334-338.

10. Siegel CA. Lost in translation: helping patients understand the risks of inflammatory bowel disease therapy. Inflamm Bowel Dis. 2010;16: 2168-2172.

11. Siegel CA. Shared decision making in inflammatory bowel disease: helping patients understand the tradeoffs between treatment options. Gut. 2012;61:459-465.

12. Shah SL, Siegel CA. Increasing patient activation could improve outcomes for patients with inflammatory bowel disease. Inflamm Bowel Dis. 2015;21:2975-2978.

13. Triantafillidis JK, Merikas E, Georgopoulos F. Current and emerging drugs for the treatment of inflammatory bowel disease. Drug Des Devel Ther. 2011;5:185-210.
14. Johnson FR, Hauber B, Ozdemir S, et al. Are gastroenterologists less tolerant of treatment risks than patients? Benefit-risk preferences in Crohn's disease management. J Manag Care Pharm. 2010;16:616-628.

15. Gonzalez J, Williams JW Jr, Noel PH, et al. Adherence to mental health treatment in a primary care clinic. J Am Board Fam Pract. 2005;18: 87-96.

16. Vlasnik JJ, Aliotta SL, DeLor B. Medication adherence: factors influencing compliance with prescribed medication plans. Case Manager. 2005;16:47-51.

17. Sawtooth Software Inc. 2013. Technical Paper Series. The CBC system for choice-based conjoint analysis (version 8). Available from: https:// www.sawtoothsoftware.com/download/techpap/cbctech.pdf. Accessed July 11, 2017.

18. National Institute for Health and Care Excellence: Guidance. National Clinical Guideline Centre. Ulcerative colitis: management in adults, children and young people. London: Royal College of Physicians (UK); 2013.

19. Johnson FR, Ozdemir S, Mansfield C, et al. Crohn's disease patients' risk-benefit preferences: serious adverse event risks versus treatment efficacy. Gastroenterology. 2007;133:769-779.

20. Gray JR, Leung E, Scales J. Treatment of ulcerative colitis from the patient's perspective: a survey of preferences and satisfaction with therapy. Aliment Pharmacol Ther. 2009;29:1114-1120.

21. Lichtenstein GR, Waters HC, Kelly J, et al. Assessing drug treatment preferences of patients with crohn's disease: a conjoint analysis. Patient. 2010;3:113-123.

22. Sylwestrzak G, Liu J, Stephenson JJ, et al. Considering patient preferences when selecting anti-tumor necrosis factor therapeutic options. Am Health Drug Benefits. 2014;7:71-81.

23. Allen PB, Lindsay H, Tham TC. How do patients with inflammatory bowel disease want their biological therapy administered? BMC Gastroenterol. 2010;10:1.

24. Bewtra M, Fairchild AO, Gilroy E, et al. Inflammatory bowel disease patients' willingness to accept medication risk to avoid future disease relapse. Am J Gastroenterol. 2015;110:1675-1681.

25. Sichtmann C, Wilken R, Diamantopoulos A. Estimating willingness-topay with choice-based conjoint analysis - can consumer characteristics explain variations in accuracy? Br J Management. 2011;22:628-645.

26. Baars JE, Markus T, Kuipers EJ, et al. Patients' preferences regarding shared decision-making in the treatment of inflammatory bowel disease: results from a patient-empowerment study. Digestion. 2010;81: 113-119.

27. Dignass A, Lindsay JO, Sturm A, et al. Second European evidence-based consensus on the diagnosis and management of ulcerative colitis part 2 current management. J Crohns Colitis. 2012;6:991-1030.

28. Dignass A, Van Assche G, Lindsay JO, et al. The second European evidence-based Consensus on the diagnosis and management of Crohn's disease: current management. J Crohns Colitis. 2010;4:28-62.

29. Gomollon F, Dignass A, Annese V, et al. 3rd EUROPEAN Evidencebased consensus on the diagnosis and management of Crohn's disease 2016: part 1: diagnosis and medical management. J Crohns Colitis. 2017; $11: 3-25$.

Patient Preference and Adherence

\section{Publish your work in this journal}

Patient Preference and Adherence is an international, peer-reviewed, open access journal that focuses on the growing importance of patient preference and adherence throughout the therapeutic continuum. Patient satisfaction, acceptability, quality of life, compliance, persistence and their role in developing new therapeutic modalities and compounds to optimize

\section{Dovepress}

clinical outcomes for existing disease states are major areas of interest for the journal. This journal has been accepted for indexing on PubMed Central. The manuscript management system is completely online and includes a very quick and fair peer-review system, which is all easy to use. Visit http://www. dovepress.com/testimonials.php to read real quotes from published authors. 